UDK: 28-31:82-5

Izvorni naučni rad

Primljeno: 07.05.2019.

Prihvaćeno za štampu: 31.5.2019.

dr.sci. Esmir M. Halilović, docent

Univerzitet u Zenici

Islamski pedagoški fakultet

esmir_b@yahoo.com

\title{
VRIJEME FITNE I POJAVA MEVDU' PREDAJA
}

\section{Sažetak}

$U$ ovom radu se tretira fenomen pojavljivanja mevdu' predaja. Izmišljanje predaja i pripisivanje istih Allahovom Poslaniku, s.a.v.s., je ogroman problem koji je zadesio muslimane relativno rano u historiji islamske civilizacije a čije posljedice se osjećaju i danas. Radom se pojašnjava vrijeme nastanka ovakvih predaja, odgovor hadiskih učenjaka u vidu temeljitog provjeravanja seneda, formiranja prvih hadiskih disciplina $i$ sl. Takoder se navode stavovi meritornih učenjaka iz oblasti Terminologije hadisa u pogledu citiranja ovakvih predaja, njihovoj upotrebi, načinima otkrivanja apokrifnih predaja $i$ sl. Govori se i o pobudama osoba koje su potvarale predaje a koje se $i$ danas mogu naći zastupljene u javnom diskursu tumačenja islama na lokalnom ili globalnom nivou.

Ključne riječi: hadis, sunnet, bid'at, mevdu', fitna

\section{Uvod}

Islamsko društvo je nakon Hilafeta Omera, r.a., zapalo u krizu. Ta kriza (ar. "fitnet") kulminirala je ubistvima hazreti Osmana, r.a., hazreti 'Alije, r.a., i hazreti Husejna, r.a. U to nesretno i teško vrijeme javljaju se prve frakcije među muslimanima. Dolazi do masovnog pojavljivanja novotarija u vjeri te je za sve to tražen bilo kakav oslonac pomoću kojeg bi se poduprla određena ideja. Tada dolazi do pojave apokrifnih tj. 
izmišljenih predaja („hadisa“c) ${ }^{1}$ tj. riječi koje pripisuju Poslaniku, s.a.v.s., ali su čiste potvore na njega. Svi islamski učenjaci se slažu da se ovo počinje događati sredinom prvog stoljeća po Hidžri. ${ }^{2}$ Zbog svega toga počinje se voditi daleko veća briga o samom senedu.

Imam Muslim bilježi interesantnu predaju od Muhammeda b. Sirina (umro 110. H. god.): „U početku, hadiski učenjaci nisu nužno zahtjevali sened, ali kada je došlo do fitneta (civilnog rata među muslimanima) oni su počeli govoriti: „Navedite nam svoje prenosioce!“ $\mathrm{Pa}$ ako bi oni bili od sljedbenika Sunneta, njihove predaje su se prihvatale a ako bi bili od sljedbenika bid'ata (novotarija u vjeri), njihove bi se predaje odbacivale! ‘3

\section{Vrijednosti i važnosti seneda}

Možemo kazati da je sened jedna od odlika i specifičnosti islama i islamskih nauka i do njegovog profiliranja i naučnog izučavanja dolazi veoma brzo nakon što se uvidjelo da postoji bojazan od iskrivljivanja vjere, vjerskih propisa i načela. Nije poznato da je i jedna civilizacija vodila toliko brige o ispitivanju ispravnosti predaja koje su do njih došle. Šta više i vjerske knjige kao što su Tevrat, Zebur i Indžil su ostale bez seneda, tj. zapisane su mnogo kasnije nego su objavljene i to desetinama i stotinama godina kasnije, a samim tim su i iskrivljene na različite načine.

Ebu Hatim (tj. Ibn Hibban) o položaju seneda u islamu kaže: „Od kada je Allah, dž.š., stvorio Adema, nije postojao ni jedan narod koji je bio toliko brižan u čuvanju tradicije svojih poslanika, kao što je ovaj Ummet!“

Briga za senedom je blisko povezana i sa putovanjem u potrazi za znanjem a posebno saznavanjem određenih hadisa od Allahovog

\footnotetext{
${ }^{1}$ Kako je o ovome periodu i izmišljenim hadisima već opširno pisao naš uvaženi profesor dr. Šefik Kurdić, čitaoce toplo upućujemo na njegovo djelo „Apokrifni hadisi“" koje ćemo nešto kasnije spominjati u radu.

${ }^{2}$ Sibai' navodi da se hadisi počinju izmišljati po prvi puta tačno 40.-e godine po Hidžri, a radi političke krize koja je pogodila islamski Ummet te godine.

${ }^{3}$ Prema Rahawan, Muhammad S. „Hadith Terminology and Classification“, Rijad: International Islamic Publishing House, 2012. god., str.: 35.
} 
Poslanika, s.a.v.s. Ibrahim b. Edhem je kazao: „Uzvišeni Allah otklanja nedaće od ovoga Ummeta zbog putovanja u potrazi za hadisom!“44

Na ovaj način vidimo da i u prvo doba islama izučavanje hadisa daje snažan impuls internacionalizaciji znanja i učenja, otvorenosti znanja za sve, razvoju kritičke misli.

Upravo putem seneda se lahko može ustanoviti (ne)vjerodostnojnost bilo kojeg hadisa. Tako je putem seneda sačuvan sunnet! Da nije seneda

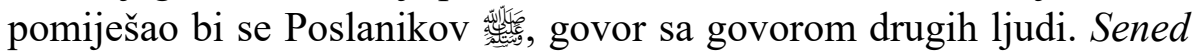
je također efikasna brana laži, potvori i sl. Neki objektivni orijentalisti su priznali ovakav položaj seneda pa su kazali da je najveća intelektualna aktivnost $\mathrm{u}$ historiji ljudskog roda - koja je bila bazirana na jednu specifičnu znanost, bila upravo ona koja je brinula o senedu i izučavanu istog. Nabrojali su više stotina hiljada učenjaka u prvim stoljećima islama koji su se bavili ovom izuzetno važnom naukom.

O vrijednosti i važnosti seneda se navode brojne izreke učenjaka. Tako 'Abdullah b. Mubarek kaže:

$$
\text { الإسناد من الدين ولولا الإسناد لقال من شاء ما شاء }
$$

„Sened je od stvari vjere! Da nije seneda ko bi šta htio - rekao bi!“65 Es-Sevri je rekao:

$$
\text { الإسناد سلاح المؤمن ، إذا لم يكن معه سلاح فبأي شيء يقاتل }
$$

"Sened je oružje vjernika. Ako nema seneda čime da se bori?",

Imam Evzai je rekao:

$$
\text { ما ذهاب العلم إلا ذهاب الإسناد }
$$

"Neće nestati nauke (hadisa) dok ne nestane seneda!"7

Neki od njih su poredili hadis bez seneda sa kućom bez krova i temelja! To su i spjevali u riječima:

\footnotetext{
${ }^{4}$ Ibid.

${ }^{5}$ Imam Hakim, „Ma'rifetu 'ulumil-hadis“, str: 6.

${ }^{6}$ Neki ovu izreku pripisuju imamu Neveviju.

${ }^{7}$ Ibidem.
} 

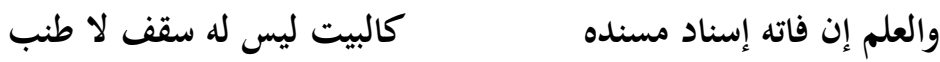

Znanje bez seneda

Kao kuća bez krova i temelja!

Paralelno sa velikom brigom o senedu, javlja se i izuzetno značajna kritička misao u pogledu prihvatanja ili neprihvatanja hadisa i hadiskih znanosti od određenih ljudi.

Pitali su Zejda b. Ebi Unejsa o njegovom bratu, a on je rekao: „Ne prihvatajte (hadise) od moga brata!“ Ali b. El-Medinija su pitali o njegovom ocu kao prenosiocu, a on je rekao: „Pitajte nekoga drugog o njemu!" kada su ga ponovo pitali, on je pognuo glavu, a onda je podigao i rekao: „Radi se o vjeri, moj otac je slab prenosilac!“، 8

Oba ova primjera nam govore kolika je briga bila posvećena očuvanju vjere u tim sudbonosnim trenucima za islam i muslimane.

\section{Mevdu' „hadis“ -}

Posebna briga učenjaka hadiskih znanosti bila je u pogledu pronalaženja i identificiranja tzv. mevdu' predaja koje se pojavljuju, kako smo već kazali u doba fitne te se takve predaje sve više šire $\mathrm{i}$ multipliciraju velikom brzinom od tog vremena.

Jezičko snačenje riječi mevdu' je da je to nešto podmetnuto, apokrifno, izmišljeno.

Terminološka definicija mevdu'a je da je to izmišljotina i laž koja se

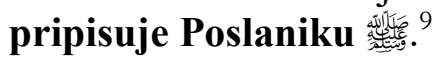

Glavna karakteristika mevdu'a je da se on sukobljava sa osnovnim temeljima i principima islama, zasnovanim na Kur'anu i vjerodostojnom sunnetu. ${ }^{10}$ Ukoliko se neki ravija optuži za laž na

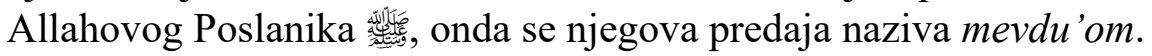

\footnotetext{
${ }^{8}$ Ibn Hibban u „El-Medžruhin“, 2/15. Iste predaje bilježi i El-Hatib el-Bagdadi u svome djelu.

${ }^{9}$ Ibnus-Sallah, nav. djelo, str: 201 i dr. M. Tahhan, cit. djelo, str: 111.

${ }^{10}$ Amr Abdul-Mun'im Sulejm, ,Tejsiru 'ulumil-hadis lil-mubtedi'in“, str.: 61.
} 


\section{Položaj mevdu'-predaja}

Učenjaci ovu vrstu predaja smatraju najgorom vrstom slabih hadisa,

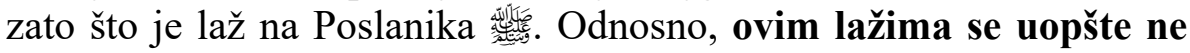
može reći da su hadisi, nego laži. Neki učenjaci ovo čak ne smatraju vrstom slabog hadisa, nego posebnom vrstom izmišljotina. Međutim, kako se navedene predaje predstavljaju kao hadisi onda je neophodno da se oni argumentovano pojašnjavaju i spriječe manipulacije sa vjerom i vjerskim propisima.

\section{Propis prenošenja mevdu' predaja}

Učenjaci kažu da onaj koji zna da je neki hadis mevdu' ne smije prenositi taj hadis (tj. to mu je haram), osim zbog objašnjavanja da je

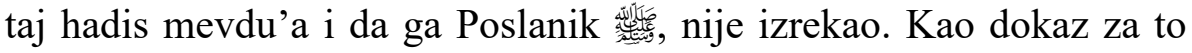
uzimaju hadis kojeg bilježi Imam Nevevi u komentaru Muslimovog Sahiha:

$$
\text { مَنْ حَدَّثَ عني بحديث يُرَى أنه كَذِبُ فهو أحد الكاذبين }
$$

“'Ko bude od mene prenosio hadis, za koji se vidi da je laž, onda je on jedan od lažljivaca." 11

O tome koliki je ovo grijeh, najbolje nam govori stav istaknutog islamskog učenjaka: Imama Ebu Muhammeda el-Džuvejnija koji je rekao:

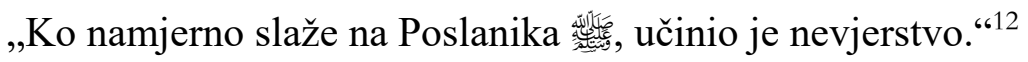

\section{Kako su lažovi izmišljali mevdu' hadise?}

1) Lažljivac izmisli riječi metna hadisa te im doda fiktivni sened, govoreći da su to Poslanikove 留偠, riječi.

2) Lažljivac uzme govor nekog mudrog ili poznatog čovjeka te mu doda

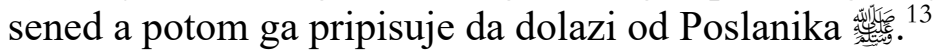

\footnotetext{
${ }^{11}$ Uvod u Muslimovu zbirku hadisa sa komentarom, 1/62.

${ }^{12}$ Uporedi: M. Handžić, cit. djelo, str: 103.

${ }^{13}$ V: Dr. M. Tahhan, „Tejsiru mustalehil-hadis“, str: 112.
} 


\section{Kako se poznaje da je hadis mevdu'?}

Učenjaci hadiskih znanosti prepoznaju mevdu' predaje na nekoliko načina. Dr. M. Tahhan navodi sljedeće ${ }^{14}$ :

1) $\mathrm{Na}$ osnovu priznavanja onoga koji je izmislio hadis, kao što je

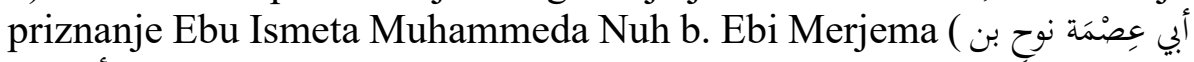
da je izmislio vrijednosti učenja svake sure iz Kur'anu i to

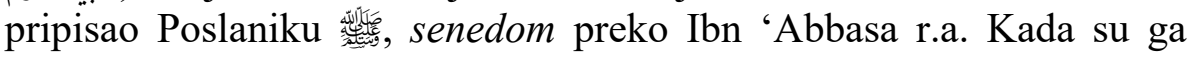
upitali: „Odakle ti ovi hadisi koje prenosiš od 'Ikrime od Ibn 'Abbasa r.a., o vrijednostima svake sure?“ On je odgovorio: „Vidio sam ljude da su se okrenili od Kur'ana i zabavili se Ebu Hanifinim fikhom, kazivanjima o vojnama od Muhammeda b. Ishaka, pa sam izmislio ove hadise kao preventivu!"“15

2) Da se utvrdi da je predaja patvorena na način da se dokaže laž kod samog prenosioca te predaje. Naprimjer da tvrdi da neku predaju prenosi od šejha koji je umro prije njegovog rođenja i sl.

3) Da čovjek koji ima određenu osobinu pristrasnosti nekome ili nečemu prenosi hadis o vrijednosti toga; npr. Rafidija prenosi hadis o vrijednostima Ehlu-l-Bejta (قرينة في الراوي(16)

4) Da ono što se prenosi u toj predaji bude u suprotnosti sa jasnim kur'anskim tekstovima, ili ljudskim razumom i sl. (قرينة في المروزي).

\section{Pobude lažova i njihove vrste}

Kroz muslimansku historiju, lažovi koji su izmišljali hadise su imali različite pobude i ciljeve. Najčešći su sljedeće:

1. Želja za približavanje Allahu. Jedan dio lažaca na Poslanika 能信, je to radio iz „,dobrih pobuda“"17 , tako što su izmišljali hadise u kojima su ljude podsticali na činjenje dobrih dijela, i hadise u kojima su izmišljali kazne za činjenje ružnih dijela. Ovo je vrsta lažaca koji se ubrajaju u pobožnjake i dobre ljude. To je ujedno i najgora vrsta lažaca i falsifikatora hadisa, jer su ljudi prihvatali njihove izmišljotine vjerujući

\footnotetext{
${ }^{14}$ Ibid.

${ }^{15}$ Ibnus-Sallah, nav. djelo, str: 206.

${ }^{16}$ Tahhan, cit. djelo, str.:112.

${ }^{17}$ Ibnus-Sallah, nav. djelo, str: 204.
} 
im. Jedan od tih falsifikatora je bio i Mejsere b. 'AbduRabbih. Ibn Hibban prenosi od Ibn Mehdija da je rekao: „Rekao sam Mejseru b. 'AbduRabbehu:

$$
\text { من أين جئت بهذه الأحاديث، من قرأ كذا فله كذا ؟ قال : وضعتُها أُرَغِبِ الناسَ }
$$

„Odakle ti toliki hadisi o vrijednostima učenja ovoga ili onoga?“ On mi je rekao: „Izmislio sam ih da ljude podstaknem na činjenje dobra!“(18

\section{Pomaganje svojoj političkoj, mezhebskoj ili nekoj drugoj} pripadnosti. Kada su se pojavile političke razlike među muslimanima, a nakon čuvene smutnje koja je kulminirala ubistvom h. Osmana, r.a., pojavile su se i razni ljudi koji su izmišljali hadise kojima pokušavaju jačati svoju pripadnost nekoj grupaciji i sl. Takvi su bili šije, Haridžije i dr. Primjer za ovo je hadis:

$$
\text { علئُ خير البشر ، من شكَُّ فيه كفر }
$$

„Alija je najbolji čovjek, ko u to sumnja on je nevjernik!““

3. Napadi na islam. Skupina koja je također izmislila mnogo hadisa su brojni nevjernici i neprijatelji islama koji nisu uspjeli islamu nauditi javno, nego su svoje prljave aktivnosti protiv islama usmjerili na njegovu unutrašnjost. Tako su izmislili brojne hadise kojima su željeli da nanesu štetu islamu, i dovedu ljude u sumnju po pitanju islama. Jedan od ovih lažova je bio i Muhammed b. Se'id eš-Šami, koji je izmislio hadis:

$$
\text { أنا خاتم النبيين لا نبي بعدي إلا أن يشاء الله }
$$

"Ja sam pečat svim vjerovjesnicima, nema vjerovjesnika nakon mene, osim ako Allah, dž.š., to bude želio." 19

4. Dodvoravanje vlastima i vladarima. Neki od ljudi željnih položaja i blizine sa vladarima i bogatašima su izmišljali hadise koji ovima odgovaraju. Tako je Gijas b. Ibrahim en-Neha'i el-Kufi ušao kod halife el-Mehdija, kada se on igrao sa golubom, pa je odmah izmislio sened

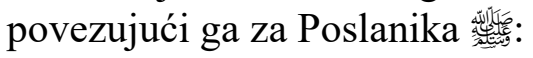

$$
\text { لا سَبَق إلا في نَصْل أو حُفٍِ أو حافر أو جَنَاح }
$$

\footnotetext{
18 Tedribur-ravi, 1/283.

19 Tedribur-ravi, 1/284.
} 
„Nema natjecanja osim sa oružjem, devama, borbenim životinjama (konjima, magarcima) i letećim životinjama“. U ovom slučaju on je u vjerodostojni hadis koji bilježi Ebu Davud ubacio riječ جَنَّاح "ili sa letećim životinjama", želeći se time dodvoriti El-Mehdiju. El-Mehdi je pronikao u njegovu namjeru pa je odmah naredio da se golub zakolje.

5. Sticanje bogatstva. Neki lašci su najviše izmišljali hadise tako što su od ljudi naplaćivali da im govore čudnovate stvari, te na taj način izmišljali predaje. Jedan od ovih je i Ebu Se'id el-Medaini (أبي سعيد) (المدائني

6. Sticanje popularnosti. Neki su pak željeli da se njihovo ime pročuje kako oni prenose neki čudnovat hadis koji nikome drugom nije poznat. Na ovaj način su željeli da se njihovo ime veliča i da ljudi žude da ih čuju. Od ovih su bili i Ibn Ebi Dihje - ابن أبي دحية, i Hammad en-Nesibi حماد النَّصِيبي.

الكَكَّامِيَّة - Kerramijje, smatrali da je dozvoljeno izmišljati hadise kako bi ljude podstakli na činjenje dobrih djela, a odvratili ih od činjenja ružnih rijela. ${ }^{20}$ Kao dokaz za ovo su uzimali hadis: „Ko na mene namjerno slaže, kako bi ljude odveo u zabludu, neka bude spreman na postelju od vatre!“", Ovaj dodatak „kako bi ljude odveo u zabludu“ nije vjerodostojan.

Na osnovu ovoga, oni su govorili: „Mi ne lažemo protiv njega, mi lažemo za njega!‘ 21

Nema sumnje da je ovakav stav van svake pameti, i u potpunosti je u suprotnosti sa Kur'anom i sunnetom.

Ono što je danas evidentno u pogledu tumačenja vjere jeste da i danas nažalost možemo naći slične motive i pobude kod različitih učenjaka i kvaziučenjaka koji ne prezaju od bilo čega kako bi postigli svoje nečasne i prizemne ciljeve. Na ovaj način se slika vjere nerijetko iskrivljuje kako kod muslimana, tako i kod nemuslimana, a islam se pretvara u nešto što on svakako nije.

Najpoznatija klasična djela iz ove oblasti su:

\footnotetext{
${ }^{20}$ Ibnus-Sallah, nav. djelo, str: 204.

${ }^{21}$ V: Dr. M. Tahhan, cit. djelo, str: 72.
} 
- كتاب الموضوعات od Ibnul-Dževzija. Ovo je jedna on najstarijih knjiga o ovome. Ipak, u ovoj knjizi se nalazi i veliki broj hadisa koji nisu izmišljeni. Zbog ovoga su učenjaci kazali da Ibnul-Dževzi veoma lahko neki hadis klasificira kao izmišljen. (متساهل في الحكم على الحديث بالوضع). Zbog toga je bio često kritikovan. ${ }^{22}$ Naime, izmišljenim je proglasio čak i neke hadise kod imama Muslima i imama Ahmeda. ${ }^{23}$

- اللآليء المصنوعة في الأحاديث الموضوعة -od Imama Sujutija. Ovo djelo je ustvari prerađeno prethodno djelo, sa manjim dodacima.

- djelo je napisao Ibn Irak elKenani. Ovo djelo je pak samo skraćena verzija prethodno spomenutog Sujutijevog djela.

- Iznimno važno i kvalitetno djelo o izmišljenim hadisima je napisao uvaženi prof.dr. Šefik Kurdić pod nazivom „Apokrifni hadisi - zbirka lažnih hadisa koji se koriste u narodu i literaturi“, Novi Pazar: ElKelimeh, 2010. god. a koje je prvo djelo ove vrste na bosanskom jeziku.

\section{Zaključak}

Izmišljanje hadisa se relativno rano javlja $\mathrm{u}$ historiji islamske civilizacije. Fabriciranje lažnih predaja koje su pripisivane Poslaniku, s.a.v.s., učinjeno je zbog različitih razloga i motiva. Zbog svega toga se pojavio veliki broj ovakvih predaja. Islamski učenjaci su učinili ogromne napore kako bi sačuvali autentični Sunnet Allahovog Poslanika, s.a.v.s. Možemo kazati da što su bili veći napadi na islam i Sunnet pogotovo, to je veći napor islamskih učenjaka bio da se adekvatno odgovori na sve te napade. $U$ tom pogledu, javljaju se veoma rano osnovi hadiskih znanosti, sakupljaju se hadisi u hadiske zbirke, identificiraju se izmišljene predaje, klasificiraju se hadisi po različitim osnovama... Preduvjet za sve to je bila posebna briga o senedu koja će se kasnije razviti u jednu od temeljnih disciplina unutar Terminologije hadisa.

\footnotetext{
${ }^{22}$ Vidi: Ibnus-Sallah, nav. djelo, str: 204.

${ }^{23}$ Vidi: Mustafa El-Adevi: „Tejsiru mustalehil-hadis fi sual ve dževab“, str: 25.
} 


\section{Literatura}

1. Handžić, Mehmed, „Uvod u tefsirsku i hadisku nauku“, Sarajevo: Gazi Husrevbegova medresa, 1972 god.

2. Karalić, Mahmud, „Hadis i hadiske znanosti“, Novi Pazar: ElKelimeh, 2010. god.

3. Kurdić, Šefik „Apokrifni hadisi - zbirka lažnih hadisa koji se koriste u narodu i literaturi“, Novi Pazar: El-Kelimeh, 2010. god

4. Muslim, Ebu Husejn b. Hadždžadž el-Kušejri, en-Nejsaburi, "Sahihu Muslim”, Bejrut,: Darul-ihjait-turasil-arebi, bez godine izdanja.

5. Rahawan, Muhammad S. „Hadith Terminology and Classification“, Rijad: International Islamic Publishing House, 2012. god.

6. Ibnus-Sallah, imam hafiz Ebu 'Amr 'Usman b. 'Abdur-Rahman ešŠehrezuri, „Ma'rifetu enva'i 'ilmil-hadisi“, Bajrut: Darul-kutubil'ilmijje, 1423 h. god./2002 god.

7. Siba'i, dr. Mustafa, „Orijentalizam i orijentalisti - za i protiv“, prijevod Nezir Halilović, Zenica: UG Selam, 2002 god.

8. Sibai', Mustafa, dr., Es-Sunne ve mekanetuha fit-tešri' 'il-islami, Bejrut: el-Mekteb-el-islami, 4 izdanje, 1405 h. god. / 1985 god.

9. Sujuti, Dželaluddin 'Abdurrahman b. Ebu Bekr, ,Tedribur-ravi fi šerhi takribir-ravi“, Bejrut: Darul-kutubil-ilmijje, 1417h. god. / 1996 god.

10. Tahhan, Mahmud, dr., „Tejsiru mustalehil-hadis“, 11. Izdanje, Rijad: „Mektebetul-me'arif linnešr vet-tevzi'“, 1430 h. god./2010 god. 


\section{Esmir M. Halilović \\ University of Zenica \\ Islamic pedagogical faculty \\ esmir_b@yahoo.com}

Original scientific article

\section{TIME OF TEMPTATION (FITNAH) AND APPEARANCE OF MEVDU' DELIVERY}

\section{ABSTRACT}

In this paper, the phenomenon of appearance of mevdu' delivery is treated.

Inventing the delivery and attribution of the same to the Prophet of Allah, $S A W$, is a huge problem that has hit Muslims relatively early in the history of Islamic civilization, and the consequences of which are felt and today. This work clarifies the time of such deliveries, the answer of the Hadith scholars in the form of a thorough examination of seneda, the formation of the first Hadith disciplines, and etc. The views of meritorious scholars in the field of hadith terminology regarding the quotation of such traditions, their use, ways of discovering apocryphal deliveries and etc.It also speaks of the initiatives of those who pretended to fake deliveries and which can be found today in the public discourse of the interpretation of Islam at the local or global level.

Keywords: hadith, sunnah, bid'at, mevdu', fitnah 


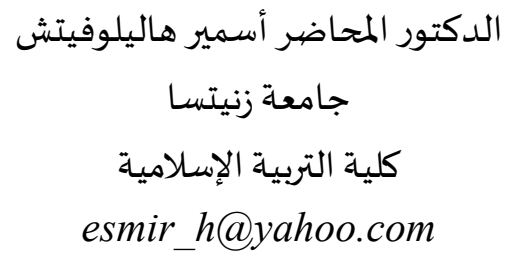

زمان الفتنة وظهور الرويات الموضيوعة

\section{الخلاصية}

يتناول هذا البحث ظاهرة حدوث الرويات الموضيوعة. وضع الأحاديث وإسنادها إلى

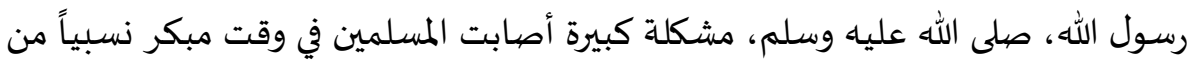

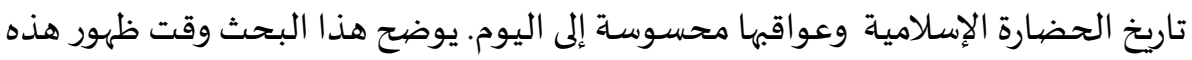
الرويات وتصدي علماء الحديث لها بفرض الفحوص الشاملة للأسسانيد، وتشكيل

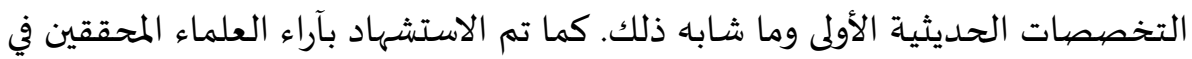

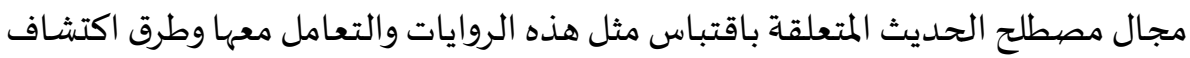

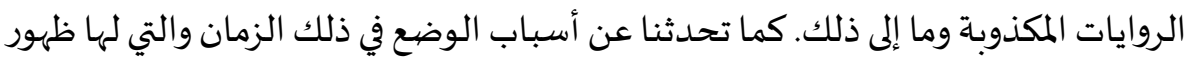

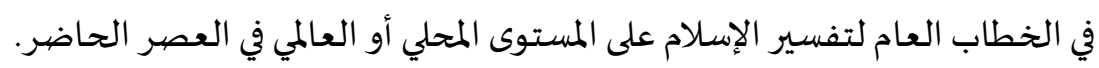

الكلمات المفتاحية: الحديث، السنة، البدعاة، الموضوع، الفتنة. 